\title{
Dependence of intestinal granuloma formation on unique myeloid DC-like cells
}

\author{
Atsushi Mizoguchi,,1,2,3 Atsushiro Ogawa,1,3 Hidetoshi Takedatsu,1,3 Ken Sugimoto,1,3 \\ Yasuyo Shimomura,1,3 Katsunori Shirane,,1,3 Kiyotaka Nagahama,1,3 Takashi Nagaishi,3,4 \\ Emiko Mizoguchi, ${ }^{2,3,5}$ Richard S. Blumberg, ${ }^{3,4}$ and Atul K. Bhan ${ }^{1,2,3}$

\begin{abstract}
'Department of Pathology Service, Immunopathology Unit, and ${ }^{2}$ Center for the Study of Inflammatory Bowel Disease, Gastrointestinal Unit, Massachusetts General Hospital, Boston, Massachusetts, USA. ${ }^{3}$ Harvard Medical School, Boston, Massachusetts, USA. 4Division of Gastroenterology, Hepatology and Endoscopy, Brigham and Women's Hospital, Boston, Massachusetts, USA. ${ }^{5}$ Division of Gastroenterology, Massachusetts General Hospital, Boston, Massachusetts, USA.
\end{abstract}

\begin{abstract}
Granulomas represent a localized inflammatory reaction that is characteristically observed in many inflammatory conditions. However, the mechanisms of granuloma formation have not been fully defined. Herein we demonstrate, by using experimental models of intestinal inflammation, that a unique CD11 ${ }^{+}$DC-like cell subset that exhibits phenotypic and functional features of immature myeloid DCs and is characterized by the expression of a macrophage marker (F4/80) produces large amounts of IL-23 and directly induces the development of granulomas under a Th1-predominant intestinal inflammatory condition. Importantly, both IL-4 and IgG contribute to the suppression of $\mathrm{F} 4 / \mathbf{8 0}^{+} \mathrm{DC}$-like cell-mediated granuloma formation by regulating the function and differentiation of this cell subset. In addition, enteric flora is required for the $\mathrm{F} 4 / \mathbf{8 0}^{+} \mathrm{DC}$-like cell-mediated granuloma formation. Collectively, our data provide what we believe are novel insights into the involvement of $\mathrm{F} 4 / \mathbf{8 0}^{+} \mathrm{DC}$-like cells in intestinal granuloma formation and demonstrate the role of host (IL-4 and $\operatorname{IgG}$ ) and environmental (enteric flora) factors that regulate this function.
\end{abstract}

\section{Introduction}

Granulomatous inflammation is a chronic inflammatory reaction, usually in response to foreign material (e.g., microorganisms, parasites), which is characterized by nodular collections of epithelioid cells (which are generally considered to represent activated macrophages) surrounded by lymphocytes (1-3). However, lesions that are classified as granulomas have diverse appearances. Although most granulomas are believed to be $T$ cell mediated, several types of immune reactions are involved in the development or suppression of granuloma formation (1-3). Interestingly, recent studies have proposed that DCs contribute to the development of granulomas in the liver and lung (4-6).

DCs represent a phenotypically heterogeneous population that is classified into several subsets, notably myeloid DCs $\left(\mathrm{CD} 11 \mathrm{c}^{+} \mathrm{CD} 11 \mathrm{~b}^{+} \mathrm{CD} 4^{+} \mathrm{CD} 8 \alpha^{-}\right.$and $\left.\mathrm{CD} 11 \mathrm{c}^{+} \mathrm{CD} 11 \mathrm{~b}^{+} \mathrm{CD} 4{ }^{-} \mathrm{CD} 8 \alpha^{-}\right)$, lymphoid DCs $\left(\mathrm{CD} 11 \mathrm{c}^{+} \mathrm{CD} 8 \alpha^{+} \mathrm{CD} 11 \mathrm{~b}^{-}\right)$, and plasmacytoid DCs $\left(\mathrm{CD} 11 \mathrm{c}^{+} \mathrm{CD} 11 \mathrm{~b}-\mathrm{B} 220^{+} \mathrm{Gr}-1^{+}\right)$. DCs are crucial components of the immune system owing to their essential role in the induction and regulation of immune responses (7-9). Even in a given subset, DCs possess considerable functional plasticity, depending on their maturation stage, environmental conditions, and location (7-9). In the intestine, several DC subsets are found depending on anatomical structures; both lymphoid and myeloid DCs are present in lymphoid follicles, such as Peyer patches (10), whereas $\mathrm{CD}_{11} \mathrm{c}^{+} \mathrm{CD} 11 \mathrm{~b}^{+} \mathrm{DCs}$ with immature phenotype represent a major DC subset in the lamina propria (LP) of small and large intestines (11-13). Intestinal DCs play a critical role in initiating local and

Nonstandard abbreviations used: $\alpha \mu \mathrm{DKO}, \mathrm{B}$ cell-deficient TCR $\alpha$ double-KO (mice); $\alpha$ IL4DKO, IL-4-deficient TCR $\alpha$ double-KO (mice); $\alpha \mu$ IL4IFNQKO, TCR $\alpha$ quadruple-KO (mice) deficient in B cells; $\alpha \mu$ IL4TKO, TCR $\alpha$ triple-KO (mice); IMD, immature myeloid DC; LP, lamina propria; QPCR, quantitative PCR; RPA, RNase protection assay.

Conflict of interest: The authors have declared that no conflict of interest exists. Citation for this article: J. Clin. Invest. 117:605-615 (2007). doi:10.1172/JCI30150. systemic immune responses by capturing antigens (e.g., from bacteria or apoptotic epithelial cells (14-16), by producing effector and regulatory cytokines $(10,17)$, and by activating B cells (18). Furthermore, specific products from enteric bacteria and intestinal epithelial cells have been shown to regulate the function of intestinal DCs $(13,17,19)$. In addition to maintaining the state of health, there are functionally distinct DC subsets that play pathogenic versus regulatory roles in the development of intestinal inflammation $(11,20-22)$. DCs also play an important role in the development of inflammatory bowel disease, a term that encompasses a group of chronic intestinal inflammatory conditions that are initiated and perpetuated by exaggerated immune responses to luminal bacterial antigens $(23,24)$. Of the 2 major forms of inflammatory bowel disease, only Crohn disease is characterized by granulomatous inflammation; ulcerative colitis is not $(2,23)$. However, the role of DCs in the development of intestinal granulomas has not yet been defined.

In this study, we demonstrate in experimental models of intestinal inflammation that a unique immature myeloid DC-like (IMD-like) subset characterized by the coexpression of F4/80 and by the production of IL-23 directly contributes to the development of intestinal granulomas and, importantly, that host (IL-4 and $\mathrm{IgG}$ ) and environmental (enteric flora) factors determine the ability of these cells to form granulomas.

\section{Results}

Absence of B cells and IL-4 induces development of intestinal granulomas. Activation of the Th1 pathway is required for the development of disease in most murine models of intestinal inflammation, some of which develop granulomas with low frequencies $(25,26)$. In contrast, TCR $\alpha$ KO mice spontaneously develop chronic intestinal inflammation that shares some features with human ulcerative colitis; this experimental colitis is mediated by Th2 cytokines (27-29). Herein we demonstrate an unexpected observation, name- 

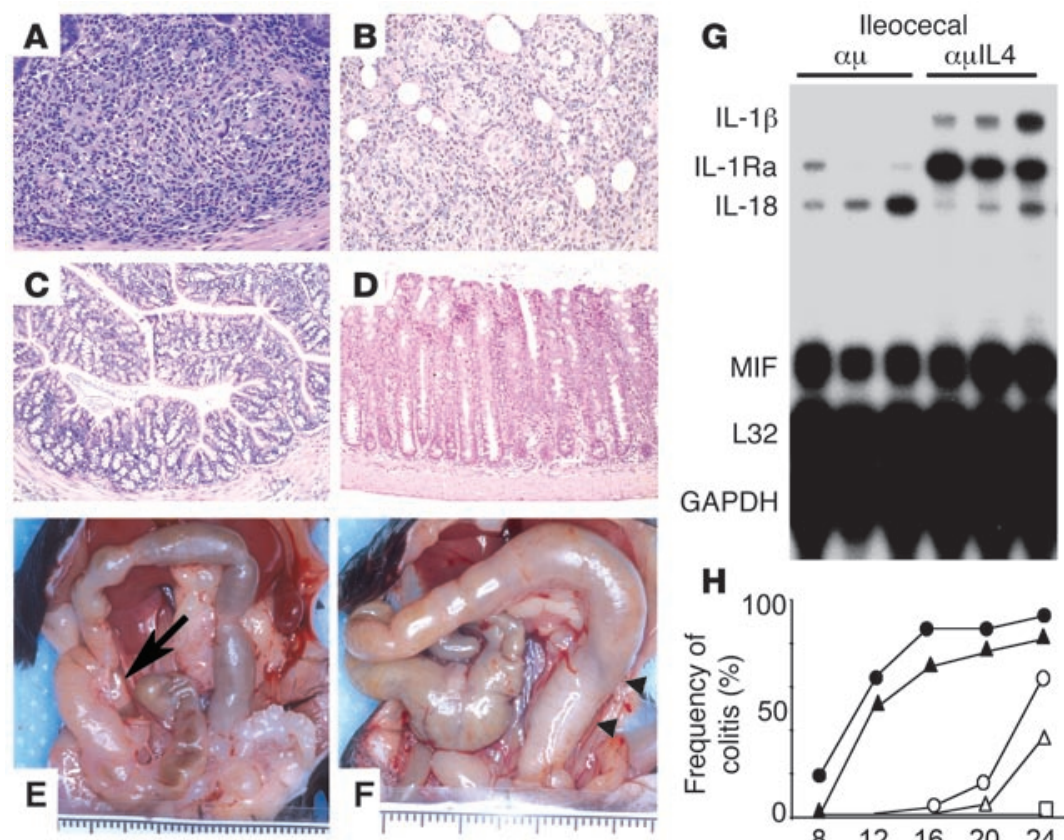

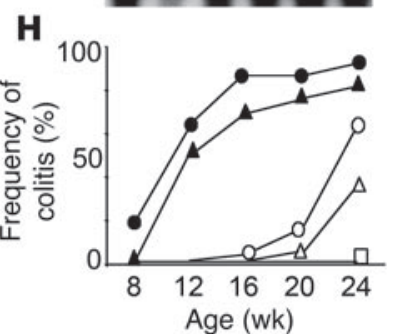

\section{Figure 1}

Development of intestinal inflammation-associated granulomas in the absence of IL-4 and B cells. (A-D) In aulL4TKO mice (24 weeks of age), granulomas are detectable within the colonic mucosa (A) as well as in the ileocecal areas (B). In contrast, granulomas are undetectable in the age-matched WT (C) and $\alpha \mu \mathrm{DKO}(\mathbf{D})$ mice. (E and F) Gross features of the large intestines of $\alpha \mu$ IL4TKO (E) and $\alpha \mu \mathrm{DKO}(\mathbf{F})$ mice at 24 weeks of age are shown. The inflammation is mostly restricted to the ileocecal junction (arrow) and proximal colon in aulL4TKO mice whereas the inflammation involves the entire colon, in particular the distal colon (arrowheads), in $\alpha \mu \mathrm{DKO}$ mice. (G) RPA shows expression of proinflammatory cytokine (IL-1 $\beta$ ) in the ileocecal junction of $\alpha \mu$ IL4TKO ( $\alpha \mu$ IL4) but not $\alpha \mu$ DKO $(\alpha \mu)$ mice (24 weeks of age). Data are representative of 2 individual experiments. (H) Frequency of colitis in WT (open squares, $n=168$ ), TCR $\alpha$ KO (open circles, $n=222$ ), $\alpha$ IL4DKO (open triangles, $n=144$ ), $\alpha \mu \mathrm{DKO}$ (closed circles, $n=218$ ) and $\alpha \mu$ LLTKKO (closed triangles, $n=104$ ) mice at various ages are shown. MIF, Macrophage migration inhibitory factor. ly, that lack of both IL-4 and B cells in TCR $\alpha$ KO mice results in development of a distinctive type of intestinal inflammation characterized by the presence of granulomas. Granulomatous inflammation was observed in the mucosa (Figure 1A) as well as in the submucosa (Figure 1B) of the colon and ileocecal junction area of $39.8 \%$ (64/161 mice) of IL-4- and B cell-deficient TCR $\alpha$ triple-KO ( $\alpha \mu \mathrm{IL} 4 \mathrm{TKO})$ mice at 24 weeks of age but not in $1102 \mathrm{TCR} \alpha \mathrm{KO}$, 548 B cell-deficient TCR $\alpha$ double-KO ( $\alpha \mu \mathrm{DKO}), 144$ IL-4-deficient TCR $\alpha$ double-KO ( $\alpha$ IL4DKO), or $113 \mathrm{WT}$ mice (Figure 1 , $\mathrm{C}$ and $\mathrm{D}$, and data not shown). Granulomas were more frequently observed in mice with marked inflammation as compared with mice with mild inflammation, but there was no statistically significant difference between these groups. The inflammation associated with $\alpha \mu I L 4 T K O$ mice was located primarily in the proximal colon, especially the ileocecal area (Figure 1E), whereas the inflammation associated with $\alpha \mu \mathrm{DKO}$ mice involved the entire colon and was especially marked in the distal regions (Figure $1 \mathrm{~F}$ ). These observations are consistent with the findings that expression of proinflammatory cytokine (IL-1 $\beta$ ) was detectable in the ileocecal junction area of $\alpha \mu$ IL4TKO but not $\alpha \mu \mathrm{DKO}$ mice (Figure 1G). At 24 weeks of age, there was no significant difference in the frequency of inflammation between $\alpha \mu$ DKO and $\alpha \mu$ IL4TKO mice (Figure 1H). The frequency of disease was much higher in $\alpha \mu$ IL4TKO mice as compared with TCR $\alpha$ KO and $\alpha$ IL4DKO mice. These results suggest that both B cells and IL-4 are required for the suppression of intestinal inflammation-associated granuloma formation. Indeed, B cells suppress Schistosoma mansoni- and Leishmania donovani-mediated granulomatous inflammation $(3,30)$.

Presence of $\mathrm{CD} 11 \mathrm{c}^{+} \mathrm{CD} 11 b^{+} \mathrm{F} 4 / 80^{\text {low }}$ cells in granuloma. RNase protection assay (RPA) analysis using RNA from the ileocecal regions revealed a significant increase in $\mathrm{F} 4 / 80$ expression in $\alpha \mu \mathrm{IL} 4 \mathrm{TKO}$ mice compared with $\alpha \mu \mathrm{DKO}$ mice (Figure $2 \mathrm{~A}$ ). Immunohistochemical analysis showed diffuse infiltration of CD4 ${ }^{+} \mathrm{TCR} \alpha^{-} \beta^{+} \mathrm{T}$ cells and aggregates of CD $11 \mathrm{~b}^{+}$cells in the areas of granulomatous inflammation (Figure 2, B and C).
Interestingly, recent studies have proposed that DCs contribute to the development of granulomas in the liver and lung (4-6). Indeed, a large number of CD $11 c^{+}$cells were also identified within granulomas of $\alpha \mu$ IL4TKO mice (Figure 2D). To characterize further the CD $11 \mathrm{c}^{+}$cells present in granulomas, cells were isolated from grossly recognizable granulomas and subjected to flow cytometric analysis. Within granulomas, $18.3 \% \pm 1.5 \%(n=12)$ of the cells had the CD $11 \mathrm{c}^{+} \mathrm{CD} 11 \mathrm{~b}^{+}$phenotype without expression of B220 or CD8 $\alpha$ (Figure 3A). Unexpectedly, the majority of $\mathrm{CD} 11 \mathrm{c}^{+} \mathrm{CD} 11 \mathrm{~b}^{+}$cells coexpressed a specific marker for macrophages, F4/80, without expression of another macrophage marker, MOMA-1 (Figure 3B and Supplemental Figures 1 and 2; supplemental material available online with this article; doi:10.1172/JCI30150DS1). The F4/80 expression was also confirmed by quantitative polymerase chain reaction (QPCR) analysis using purified CD $11 \mathrm{c}^{+}$cells from granulomas (Figure 3C). To determine whether the F4/80 $\mathrm{CD} 11 \mathrm{c}^{+}$cells represented macrophages or DCs, purified $\mathrm{F} 4 / 80^{+} \mathrm{CD} 11 \mathrm{c}^{+}$and

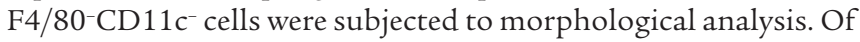
note, fine dendrites, a specific feature of DCs, were observed on the $\mathrm{F} 4 / 80^{+} \mathrm{CD} 11 \mathrm{c}^{+}$cells (Figure $3 \mathrm{D}$ ). In addition, $\mathrm{F} 4 / 80^{+} \mathrm{CD} 11 \mathrm{c}^{+}$ cells were characterized by low expression of CD86 compared with WT BM-derived mature DCs (Figure 3E). Furthermore, unlike BM-derived mature DCs, F4/80 ${ }^{+} \mathrm{CD} 11 \mathrm{c}^{+}$cells did not present antigens to $\mathrm{T}$ cells as assessed by mixed lymphocyte reactions (Figure $3 \mathrm{~F}$ ). Moreover, phagocytic activity as judged by the FITC-dextran uptake was observed in F4/80 $\mathrm{CD} 11 \mathrm{c}^{+}$cells although the activity of these cells was relatively low compared with that observed in BM-derived immature DCs (Figure 3G). In addition, the purified CD $11 \mathrm{c}^{+}$cells from the colonic LP of $\alpha \mu$ IL4TKO, $\alpha$ IL4DKO, $\alpha \mu$ DKO, TCR $\alpha$ KO, and WT mice exhibited the properties of immature DCs (data not shown). These findings identify a granuloma-associated unique cell subset that shares some phenotypic and functional properties with IMD and, unexpectedly, also expresses a macrophage marker, F4/80. 


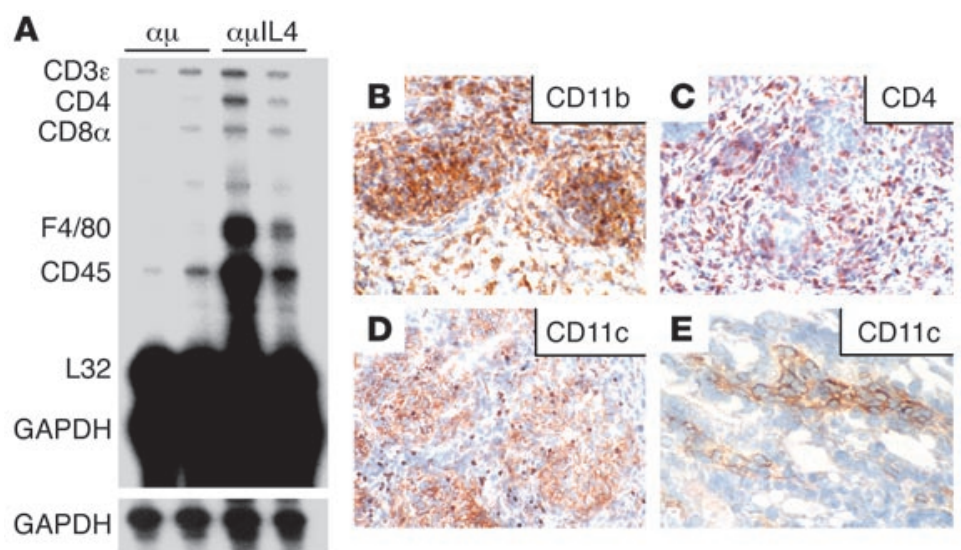

\section{Figure 2}

Cellular composition in granulomas. (A) Analysis of the cellular infiltrate at the ileocecal junction of $\alpha \mu$ IL4TKO mice with granulomas and $\alpha \mu D K O$ mice was performed by RPA using total RNA $(10 \mu \mathrm{g})$. All mice were 24 weeks of age. The bands were visualized by 12-hour exposure (top panel) and 6-hour exposure (bottom panel). (B-E) Immunohistochemical analysis of granulomas in the ileocecal junction (B-D) and colonic LP (E) of $\alpha \mu$ IL4TKO was performed using anti-CD11b (B), anti-CD4 (C), and anti-CD11c (D and E) mAbs. Findings are representative of 8 individual experiments.

IL-12p40 but not IFN- $\gamma$ is required for the development of granulomas. The experimental colitis models of Crohn disease that are characterized by the presence of granulomas have been shown to exhibit upregulation of IL-12p40 and IFN- $\gamma$ in the colon $(25,26,31)$. Indeed, RPA and ELISA analyses showed that the expression levels of IL-12p40 and IFN- $\gamma$ were significantly upregulated in the colons of $\alpha \mu$ IL4TKO mice compared with $\alpha \mu \mathrm{DKO}, \alpha \mathrm{IL} 4 \mathrm{DKO}, \mathrm{TCR} \alpha \mathrm{KO}$, and WT mice (Figure 4, A and B). To determine whether IFN- $\gamma$ is involved in the development of granulomas, TCR $\alpha$ quadruple-KO mice deficient in B cells, IL-4, and IFN- $\gamma(\alpha \mu$ IL4IFNQKO) were generated. Like $\alpha \mu I L 4 T K O$ mice, $\alpha \mu$ IL4IFNQKO mice spontaneously developed granulomatous colitis (Figure 4C).

Since the generation of TCR $\alpha$ quadruple-KO mice deficient in B cells and IL-4 as well as IL-12p40 was difficult because of the colocalization of the TCR $\alpha$ and IL-12p40 loci in the same chromosome, the role of IL-12p40 in the development of granulomas was investigated by in vivo neutralization of IL-12p40 activity by administration of specific mAbs (32). The administration of anti-IL-12p40 mAbs but not of control rat Igs contributed to the suppression of granulomas (Figure 4, D and E). These results suggest that IL-12p40 but not IFN- $\gamma$ is required for the development of intestinal inflammation-associated granulomas, consistent with a previous report showing a reduction in the size and number of polyvinylpyrrolidone-induced skin granulomas in IL-12p40 KO mice (7).

$I L-23$ that is produced by $C D 11 c^{+}$cells is regulated by IgG and IL-4. To determine whether CD $11 c^{+}$cells are a source of IL-12p40 production in $\alpha \mu \mathrm{IL} 4 \mathrm{TKO}$ mice, freshly isolated CD $11 \mathrm{c}^{+}$and CD11 $\mathrm{c}^{-}$cells were subjected to real-time PCR analysis. A significantly higher level of IL-12p40 expression was detectable in CD11 $\mathrm{c}^{+}$than in CD11 $c^{-}$cells from these mice (Figure 5A). This finding was further confirmed by using ELISA (Figure 5B). Of note, considerably greater enhancement of IL-12p40 production was observed when purified CD $11 \mathrm{c}^{+}$cells from grossly recognizable granulomas were examined (Figure 5B). IL-12p40 associates with IL-12p35 to form IL-12 or with p19 to form IL-23 (33), and DCs localized to the dis- tal small intestine have been shown to express predominantly IL-23 (34). Importantly, IL-23 has been recently found to be a crucial factor in the development of granulomas (35). Interestingly, ELISA assay showed the spontaneous production of IL-23 but not IL-12 by granulomaderived CD11 $\mathrm{c}^{+}$cells (Figure 5C).

Since the absence of B cells as well as IL-4 was necessary for the development of granulomas, the effect of IL-4 and Igs on IL-12p40 production by IMD-like cells was also examined. Interestingly, the addition of IL-4 significantly suppressed the production of IL-12p40 by CD $11 \mathrm{c}^{+}$ cells (Figure 5D). Addition of IgG purified from TCR $\alpha \mathrm{KO}$ mice with colitis also reduced the IL- $12 \mathrm{p} 40$ production by CD11 $\mathrm{c}^{+}$cells (Figure 5D). In addition, immunocomplexes made of OVA and anti-OVA IgG exhibited a suppressive effect on IL-12p40 production (Figure 5D). In contrast, $\mathrm{F}(\mathrm{ab})^{2}$ fragments failed to reduce IL-12p40 production, and addition of anti-FcR $\gamma \mathrm{II} / \mathrm{III} \mathrm{mAbs}$ inhibited IgG-mediated suppression of IL-12p40 production (Figure 5D). Interestingly, the strongest effect on the suppression of IL-12p40 production was observed when both IL-4 and IgG were added to the cultures of granuloma-derived CD $11 \mathrm{c}^{+}$cells (Figure 5D). Consistent with this response to IL-4 and IgG, CD $11 c^{+}$cells from $\alpha \mu$ IL4TKO mice expressed IL-4R $\alpha$ and FcrRII/III as defined by flow cytometric analysis (Figure 5E). These in vitro findings suggest that both IL-4 and the Fc portion of IgG contribute to the downregulation of IL-12p40 production by granuloma-associated IMD-like cells.

Since dysregulated host/enteric bacteria interactions are involved in the pathogenesis of chronic colitis (24), we determined whether specific microorganism-derived products stimulate IL-12p40 production by IMD-like cells. Purified CD $11 \mathrm{c}^{+}$cells from the colon with or without granulomas were cultured with several bacterial products that are recognized by specific pattern recognition receptors, such as TLRs and NOD2 (CARD15) (36). Interestingly, among these products, CPG (TLR9 ligand) and, to a lesser extent, loxoribine (TLR7 ligand) specifically stimulated CD11 $\mathrm{c}^{+}$cells from granulomatous intestine to produce IL-12p40 (Figure 5F). In contrast, $\mathrm{CpG}$ only slightly enhanced the production of IL-12p40 by

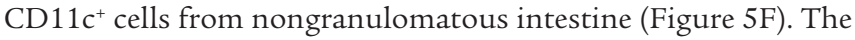
induction of IL-12p40 production by $\mathrm{CPG}$ was downregulated in the presence of IL- 4 or intact IgG but not by $\operatorname{IgG~F}(\mathrm{ab})^{2}$ fragments (Figure 5G). Furthermore, QPCR analysis revealed that both CPGstimulated and freshly isolated CD11 $c^{+}$cells from $\alpha \mu$ IL4TKO mice produced significantly more p19 (IL-23) and p40 than p35 (IL-12) (Figure $5 \mathrm{H}$ ). This result was further confirmed by ELISA (Figure 5I). Since IL-23 has been demonstrated to induce IL-17-producing $\mathrm{CD}^{+} \mathrm{T}$ cells termed $\mathrm{Th} 17$ (37, 38), IL-17A and IL-17F expression by purified $\mathrm{CD}^{+} \mathrm{T}$ cells from the ileocecal junction of $\alpha \mu \mathrm{IL} 4 \mathrm{TKO}$, $\alpha \mu \mathrm{DKO}, \alpha \mathrm{IL} 4 \mathrm{DKO}, \mathrm{TCR} \alpha \mathrm{KO}$, and WT mice was examined. Interestingly, a significant increase in IL-17A and IL-17F expression was observed in the $\mathrm{CD}^{+} \mathrm{T}$ cells from $\alpha \mu \mathrm{IL} 4 \mathrm{TKO}$ mice as compared with other mouse groups tested (Figure 5J and data not shown). These studies suggest that bacterial CpG stimulates granulomaassociated CD11c cells to produce IL-23 and that IgG and IL-4 contribute to the regulation of this production.

IMD-like cells can induce granuloma formation. To determine whether granuloma-derived IMD-like cells have the ability to induce granulomas, purified CD $11 \mathrm{c}^{+}$cells $\left(3 \times 10^{5}\right.$; more than $90 \%$ of these cells expressed F4/80) from granulomas of $\alpha \mu$ IL4TKO mice 

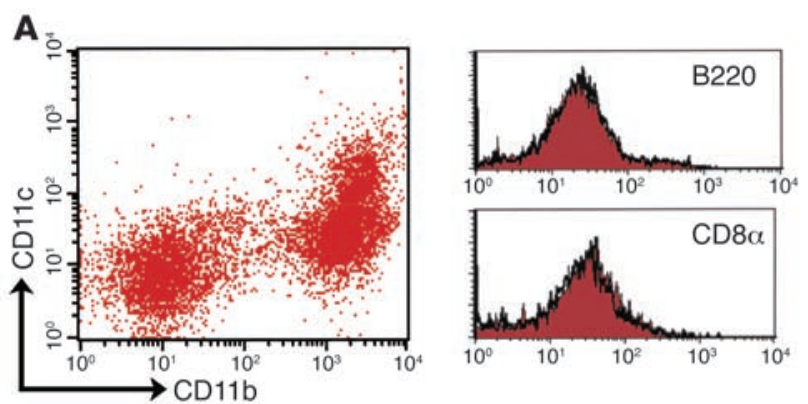

$\mathbf{E}$
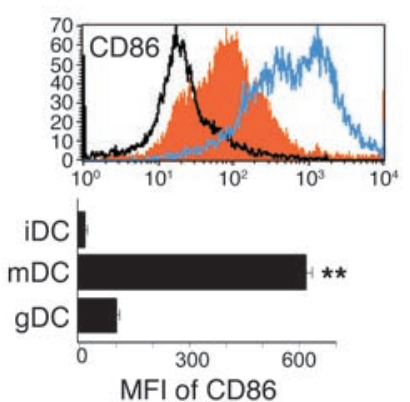

B

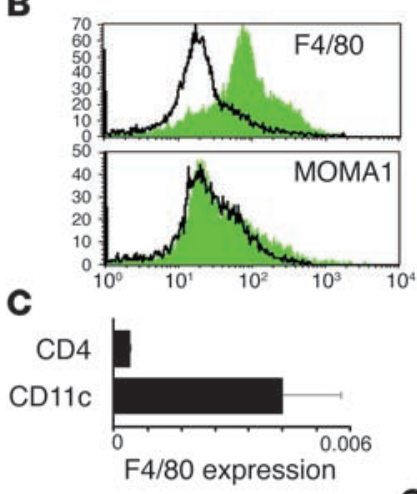

D

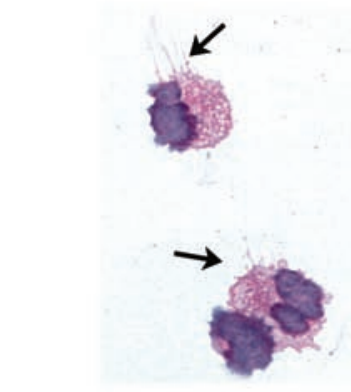

G

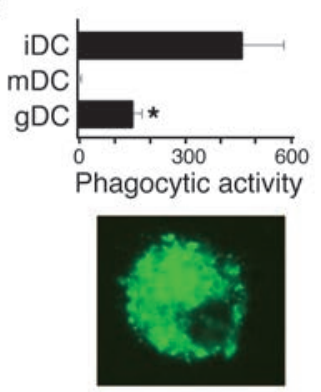

Figure 3

Granuloma-associated CD11 ${ }^{+}$cells exhibit a unique IMD-like phenotype with F4/80 expression. (A) Staining of CD11c versus CD11b (left panel) and $\mathrm{B} 220$ or $\mathrm{CD} 8 \alpha$ expression (solid red histograms, right panels) on gated $\mathrm{CD} 11 \mathrm{~b}+\mathrm{CD} 11 \mathrm{C}^{+}$cells from grossly recognizable granulomas $(n=12)$ are shown. (B) Expression $(n=9)$ of F4/80 or MOMA-1 on gated CD11b+CD11c cells are shown as solid green histograms. Black lines represent isotype control staining. (C) QPCR shows F4/80 expression by purified CD11 $\mathrm{C}^{+}$cells $(n=3)$ from granulomas and splenic CD4+ cells $(n=3)$. (D) Morphology of FACS-purified F4/80+CD11 ${ }^{+}$cells from granulomas is shown. Fine dendrites are recognized on these cells (arrows). (E) Expressions of CD86 on granuloma-derived CD11 $\mathrm{c}^{+} \mathrm{CD} 11 \mathrm{~b}^{+}$cells (solid orange histograms) and BM-derived mature DCs (blue line) are shown. Black line represents isotype control staining. The averages of CD86 mean fluorescent intensity (MFI) on BM-derived immature (iDC, $n=3)$ and mature (mDC, $n=3$ ) and granuloma-derived CD11 $\mathrm{c}^{+} \mathrm{CD} 11 \mathrm{~b}^{+}$cells $(\mathrm{gDC}, n=10)$ are summarized. (F) T cells $(\mathrm{T})$ from BALB/c mice were cultured without or with C57BL/6 mDC or gDC $(n=3)$ for 80 hours and pulsed with $1 \mu \mathrm{Ci}{ }^{3} \mathrm{H}$ for 16 hours. (G) iDC $(n=3)$, mDC $(n=3)$, and gDC $(n=3)$ were cultured with FITC-dextran at $4^{\circ} \mathrm{C}$ or $37^{\circ} \mathrm{C}$ and subjected to flow cytometric analysis. The averages of phagocytic activity are indicated as FITC-dextran MFI at $37^{\circ} \mathrm{C}$ minus FITC-dextran MFI at $4^{\circ} \mathrm{C}$. Bottom panel shows gDC cultured with FITC-dextran at $37^{\circ} \mathrm{C}$. Statistical significances are indicated by asterisks. ${ }^{* *} P<0.001 ;{ }^{*} P<0.05$.

(24 weeks of age) were directly injected into the ileocecal junction of young $\alpha \mu$ IL4TKO mice at 9 weeks of age, a time when granulomas have not yet developed. Interestingly, the local transfer of CD $11 c^{+}$cells but not mock PBS injection resulted in the development of granulomas in the recipient ileocecal junction (Figure $6, A, B$, and G). In contrast with $\alpha \mu$ IL4TKO mice, RAG-1KO mice (which do not have T or B cells), 6-month-old $\alpha \mu \mathrm{DKO}$ mice (which develop colitis in the presence of IL-4), B cell-deficient IL-4 DKO mice (which lack both B cells and IL-4 but are not prone to develop colitis), and WT mice did not develop granulomas after the local injection of $\mathrm{CD} 11 \mathrm{c}^{+}$cells from granulomas of $\alpha \mu$ IL 4 TKO mice (Figure 6, C-E, and I). These findings indicate that IMDlike cells are capable of directly inducing granuloma formation in intestine and that the host factors, including absence of IL-4, impaired B cell function, and susceptibility to inflammation, are important determinants in granuloma formation.

To determine whether the locally transferred cells were retained at the injected sites, CFSE-labeled CD $11 \mathrm{c}^{+}$cells were utilized. Interestingly, $\mathrm{CFSE}^{+}$cells with granuloma-like structure were detected at the injection sites 4 days after the cell injection (Figure 6F). To determine whether the ability of IMD-like cells to induce granuloma formation is intestine specific, granuloma-derived CD $11 \mathrm{c}^{+}$ cells were directly injected into the liver and kidney where spontaneous granuloma development was not observed even in older a $\mu$ IL4TKO mice (24 weeks of age). Surprisingly, the local transfer of $\mathrm{CD} 11 \mathrm{c}^{+}$cells was able to induce the development of granulomas in the liver and kidney of recipient young $\alpha \mu$ IL4TKO mice (9 weeks of age) (Figure 6, G-I).

$I L-4$ and IgG contribute to the suppression of IMD-like cell-mediated granuloma formation. Since intestinal inflammation-associated granulomas specifically develop in the absence of both IL-4 and $\mathrm{B}$ cells, studies were performed to determine whether IL-4 and/or IgG is actually required for the suppression of IMD-like cellmediated granuloma formation. Purified F4/80 ${ }^{+}$CD $11 c^{+}$cells $\left(3 \times 10^{5}\right)$ from granulomas of $\alpha \mu$ IL4TKO mice (24 weeks of age) were directly injected into the ileocecal junction of young $\alpha \mu$ IL4TKO mice (9 weeks of age). IL-4 (10 $\mu \mathrm{g})$ or PBS was then continuously supplied to some recipient mice for 3 weeks through a catheter from an osmotic pump that was implanted within the dorsa, as previously described (29). In other recipient mice, IgG $(1 \mathrm{mg})$ purified from TCR $\alpha$ KO or WT mice was repeatedly injected i.p. once every 3 days for 3 weeks. Notably, the IMD-like cellmediated granuloma formation was completely abolished by the delivery of IL-4 (Figure 7, A and E) but not PBS (Figure 7, B and E). 


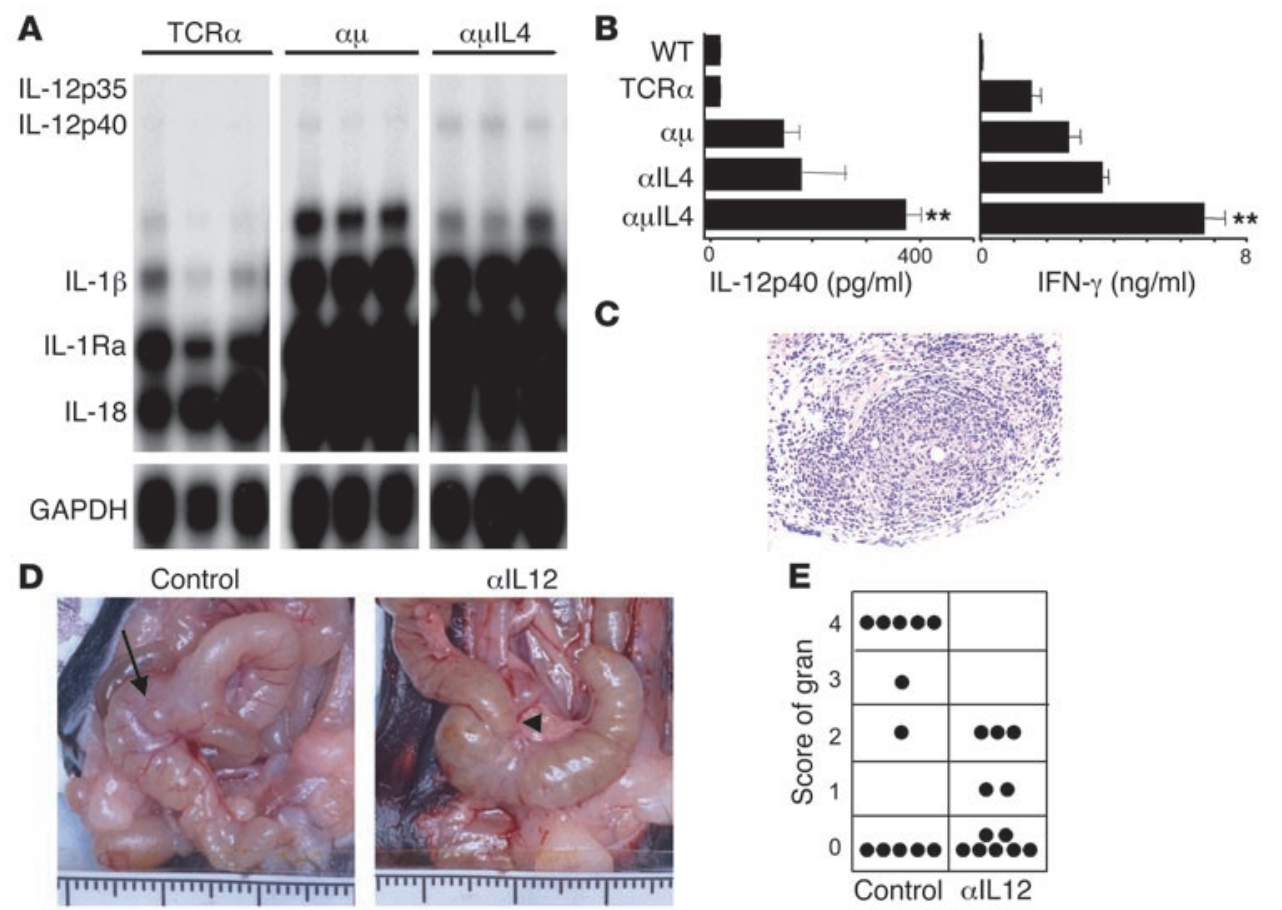

Figure 4

IL-12p40 but not IFN- $\gamma$ is involved in the development of intestinal granulomas. (A) RPA using RNA from ileocecal junction areas shows that IL-12p40 but not p35 is detectable in $\alpha \mu$ IL4TKO but not TCR $\alpha$ KO (TCR $\alpha$ ) mice (24 weeks of age). (B) Colonic LP cells $\left(2 \times 10^{5}\right)$ from WT $(n=5)$, TCR $\alpha$ KO $(n=7)$, $\alpha \mu$ DKO $(n=7)$, $\alpha$ IL4DKO ( $\alpha$ IL4) $(n=7)$, and $\alpha \mu \operatorname{IL} 4$ TKO $(n=9)$ mice were cultured for 48 hours, and the culture supernatants were subjected to ELISA. There was a significant increase $\left.{ }^{* *} P<0.001\right)$ of IL-12p40 and IFN- $\gamma$ production by colonic LP cells from $\alpha \mu \mathrm{IL} 4 \mathrm{TKO}$ mice compared with $\alpha \mu \mathrm{DKO}, \alpha \mathrm{IL} 4 \mathrm{DKO}, \mathrm{TCR} \alpha \mathrm{KO}$, and WT mice. (C) Typical granulomatous inflammation characterized by nodular collections of epithelioid cells surrounded by lymphoid cells is still detectable in $\alpha \mu$ IL4IFNQKO mice. The frequency and severity of granulomas were similar in $\alpha \mu$ IL4TKO and $\alpha \mu$ IL4IFNQKO mice (data not shown). (D and E) Anti-IL-12p40 mAbs $(0.5 \mathrm{mg})$ were administered weekly to $\alpha$ IL LTKO mice (16 weeks of age) that had developed colitis, as indicated by the presence of diarrhea, and the mice were sacrificed at 24 weeks of age. Granulomatous inflammation, identified grossly as nodular lesions, is present in the ileocecal junction area of the $\alpha \mu$ IL4TKO mice administered control Igs (arrow) but not those administered anti-IL-12p40 mAbs (arrowhead). Granulomatous inflammation was graded as follows: 0, no granulomas present; 1, aggregation of cells without definite granuloma formation that is characterized by nodular collections of epithelioid cells surrounded by lymphocytes; 2 , an occasional small granuloma present; 3 , a few large granulomas present; and 4, many granulomas present. Results are summarized in E. Gran, granulomas.

In addition, the administration of IgG from not only TCR $\alpha$ KO but also WT mice resulted in significant suppressive effect on granuloma development; however, complete abolishment of granuloma formation was not achieved, as indicated by the presence of small granuloma-like structure and lymphoid aggregates (Figure 7, C-E). Furthermore, significant downregulation (more than 4-fold) of IL-12p40 and p19 expression in the ileocecal junction area was observed in the recipient $\alpha \mu$ IL4TKO mice who received administration of IL-4 or IgG compared with those who received PBS administration (Figure 7F). These findings suggest that the ability of IMD-like cells to form intestinal granulomas is reciprocally regulated by both IL-4 and IgG.

Enteric bacteria are required for IMD-like cell-mediated granuloma formation. Since IL-12p40 and p19 expression by IMD-like cells was significantly enhanced by stimulation with the bacterial product CPG (Figure 5G), we next examined the role of enteric flora in the IMD-like cell-induced granuloma formation by locally transferring granuloma-derived IMD-like cells into the ileocecal junc- tion of $\alpha \mu$ IL4TKO mice in which enteric flora had been depleted by a combination of broad-spectrum antibiotics in their drinking water, as previously described (39). As shown in Figure 7G, the antibiotictreated mice exhibited a dramatic enlargement of the cecum, a characteristic feature of germ-free mice (40). Of note, no granuloma was identified in the ileocecal junction of 8 antibiotic-treated auIL4TKO mice that received local transfer of IMD-like cells (Figure 7G). In contrast, local IMD-like cell transfer induced granuloma formation in 3 out of 8 a IL 4 TKO mice that did not receive antibiotic treatment (Figure 7G). These findings suggest that, in addition to altered host factors (IL-4 and IgG), enteric flora is required for IMD-like cell-induced intestinal granuloma formation.

Immature DCs differentiate into IMD-like cells under immune-compromised conditions. To determine whether the ability of IMD-like cells developing in $\alpha \mu$ IL4TKO mice to form granulomas is specific for these mice, BM-derived DCs from WT mice were expanded in vitro and separated into $\mathrm{CD} 86^{-}$ $\mathrm{CD} 11 \mathrm{c}^{+} \mathrm{CD} 11 \mathrm{~b}^{+}$(immature) and $\mathrm{CD}^{2} 6^{+} \mathrm{CD} 11 \mathrm{c}^{+} \mathrm{CD} 11 \mathrm{~b}^{+}$(mature) myeloid DC subsets, then injected into the ileocecal junction of young auIL4TKO mice. The local transfer of immature (Figure 8, $\mathrm{A}$ and $\mathrm{E}$ ) but not mature (Figure 8, B and E) myeloid DCs led to the development of granulomas in the recipient $\alpha \mu$ IL4TKO mice. In contrast, the local transfer of BM-derived immature DCs from WT mice failed to induce granuloma formation in the recipient $\alpha$ IL4DKO (Figure 8, $\mathrm{C}$ and $\mathrm{E}$ ) and $\alpha \mu \mathrm{DKO}$ (Figure 8, D and E) mice. These findings suggest that IMD-derived cells are capable of inducing granuloma formation when provided with a granuloma-favoring microenvironment (absence of IL-4 and impaired B cell function).

To track donor-derived DCs in the recipient mice, IMDs from the BM of GFP transgenic mice were locally transferred into ileocecal junctions of recipient $\alpha \mu \mathrm{IL} 4 \mathrm{TKO}, \alpha \mu \mathrm{DKO}$, and $\alpha \mathrm{IL} 4 \mathrm{DKO}$ mice. Notably, F4/80 expression was induced on the transferred immature DCs in the recipient $\alpha \mu$ IL4TKO mice, as indicated by the expression of $\mathrm{F} 4 / 80$ on the transferred $\mathrm{GFP}^{+} \mathrm{CD} 11 \mathrm{c}^{+}$cells isolated from the ileocecal junction of the recipient mice as compared with the lack of $\mathrm{F} 4 / 80$ expression by $\mathrm{GFP}^{+} \mathrm{CD} 11^{+}$cells before the transfer (Figure 8F). In contrast, $\mathrm{GFP}^{+}$cells were not detectable in the cells isolated from the ileocecal junctions of recipient $\alpha \mu \mathrm{DKO}$ and $\alpha$ IL4DKO mice following local transfer of immature DCs. These findings suggest that BM-derived immature DCs differenti- 
A

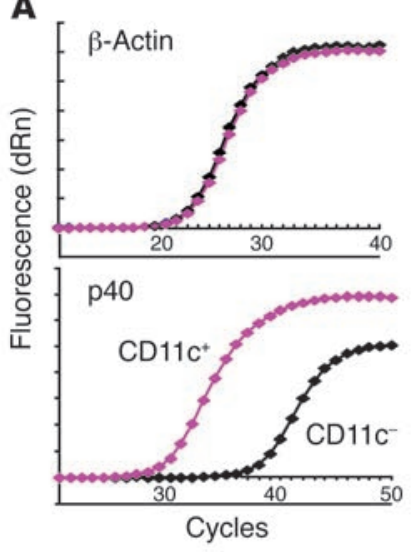

E

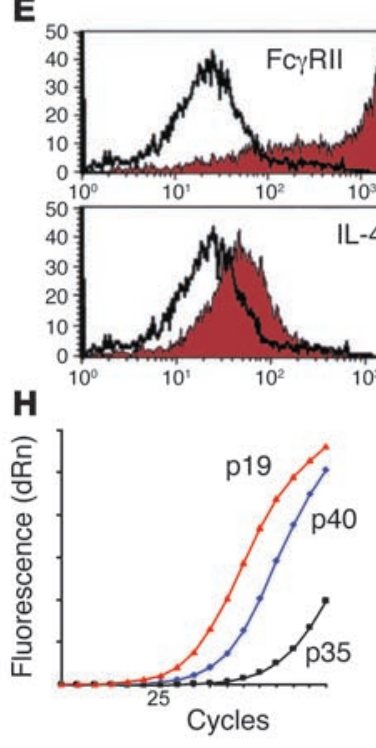

B

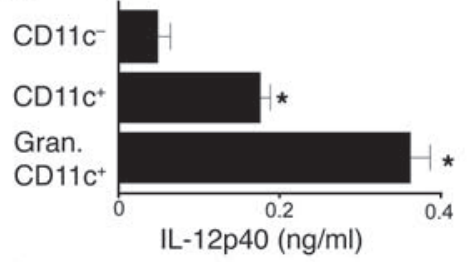

C

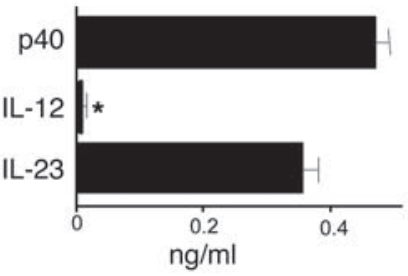

$\mathbf{F}$

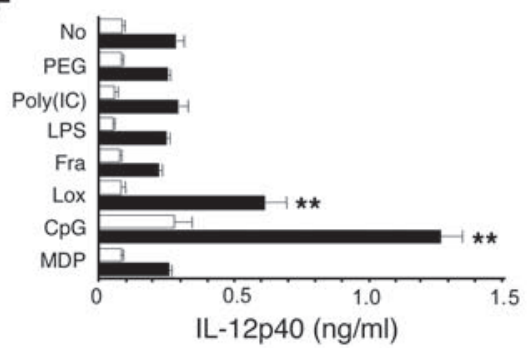

I

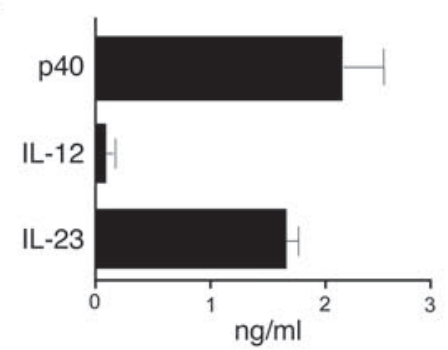

D

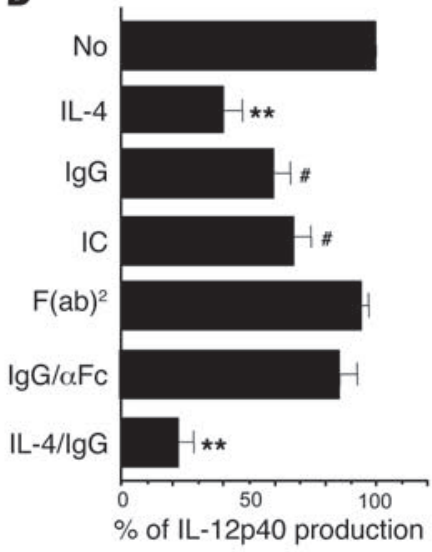

G

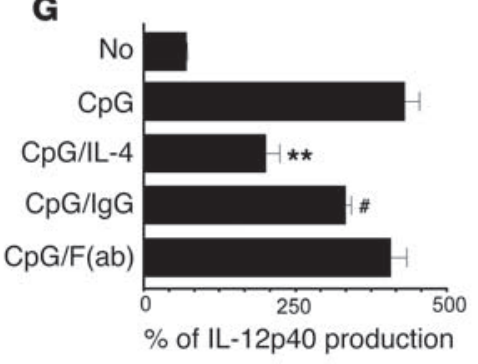

J

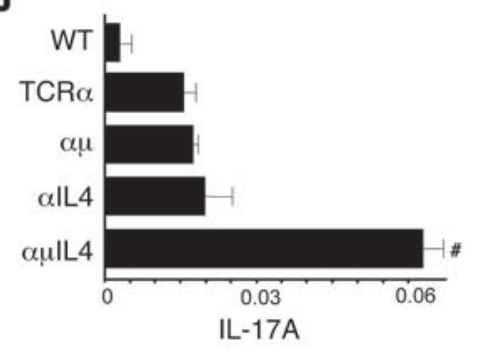

Figure 5

IL-4 and IgG suppress IL-12p40 production by IMD-like cells. (A) Expression of $\beta$-actin and IL-12p40 by CD11 $\mathrm{C}^{+}$and $\mathrm{CD} 11 \mathrm{c}^{-}$fractions from the ileocecal junction of $\alpha \mu$ IL4TKO mice. (B) IL-12p40 production by CD11 ${ }^{+}$and CD11 $\mathrm{c}^{-}$colonic fractions and CD11 $\mathrm{C}^{+}$granuloma fractions from aulL4TKO mice $(n=4-6)$. ${ }^{*} P<0.005$. (C) IL-12p40, IL-12, and IL-23 expression by CD11 ${ }^{+}$granuloma fractions $(n=3)$. ${ }^{* *} P<0.001$. (D)

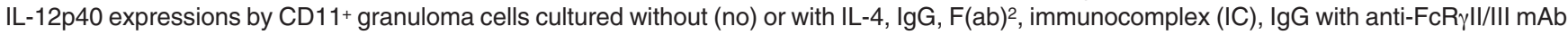
$(\mathrm{IgG} / \alpha \mathrm{FC})$, or combination of IL-4 and IgG $(\mathrm{IL}-4 / \mathrm{lgG})$. Values are averages $(n=6-9)$ of percentages of IL-12p40 production with additive divided by IL-12p40 production without additive. ${ }^{\#} P<0.01$. (E) Fc $\gamma R$ IIlb/III and IL-4R $\alpha$ expression (solid histograms) on CD11 $\mathrm{c}^{+} \mathrm{CD} 11 \mathrm{~b}^{+}$granuloma cells. (F) IL-12p40 productions by purified CD11 + cells $(n=3-6)$ from the ileocecal junction of $\alpha \mu$ lL4TKO mice with (black bars) or without (white bars) granulomas, in response to PBS (no), peptidoglycan (PEG), poly(I:C), LPS, flagellin (Fra), loxoribine (Lox), CpG, or muramyl dipeptide (MDP). (G) IL-12p40 production by CD11+ granuloma cells in response to PBS (no), CpG, or CpG plus IL-4 (CpG/IL-4), IgG (CpG/lgG), or F(ab)2 fragment $[\mathrm{CpG} / \mathrm{F}(\mathrm{ab})]$. Data represent averages of percentages of IL-12p40 production with additive divided by IL-12p40 production without additive. (H) QPCR shows IL-12p40, p35, and p19 expressions by CD11 $\mathrm{c}^{+}$granuloma cells $(n=4)$ stimulated with CpG. (I) IL-12p40, IL-12, and IL-23 production by CD11+ granuloma cells stimulated with CpG. (J) QPCR shows expression of IL-17a by purified CD4+ T cells $(n=3)$ from ileocecal junction of mice indicated. $\mathrm{dRn}$, baseline-corrected, normalized fluorescence. ${ }^{\#} P<0.01$.

ate into IMD-like cells in the absence of both IL-4 and B cells. In addition, the presence of both IL-4 and B cell deficiencies enhances the retention of immature DCs within the intestine, presumably to induce their differentiation into IMD-like cells.

\section{Discussion}

A unique DC-like subset that coexpresses CD11c and F4/80 with an immature phenotype and exhibits morphological similarity with foamy macrophages has recently been identified in the lung after infection of Mycobacterium tuberculosis, which characteristically causes granulomatous inflammation $(6,41)$. We demonstrate herein that an increase in the similar cell subset is also associated with the development of intestinal granulomas in TCR $\alpha \mathrm{KO}$ mice in the absence of both IL-4 and B cells. This CD $11 \mathrm{c}^{+} \mathrm{F} 4 / 80^{+}$cell subset present in intestinal granulomas shares several features with IMDs. These features include CD11b expression, low CD86 expression, reduced antigen-presenting capability, and enhanced phagocytic activity. Of note, this unique subset is also characterized by the presence of 

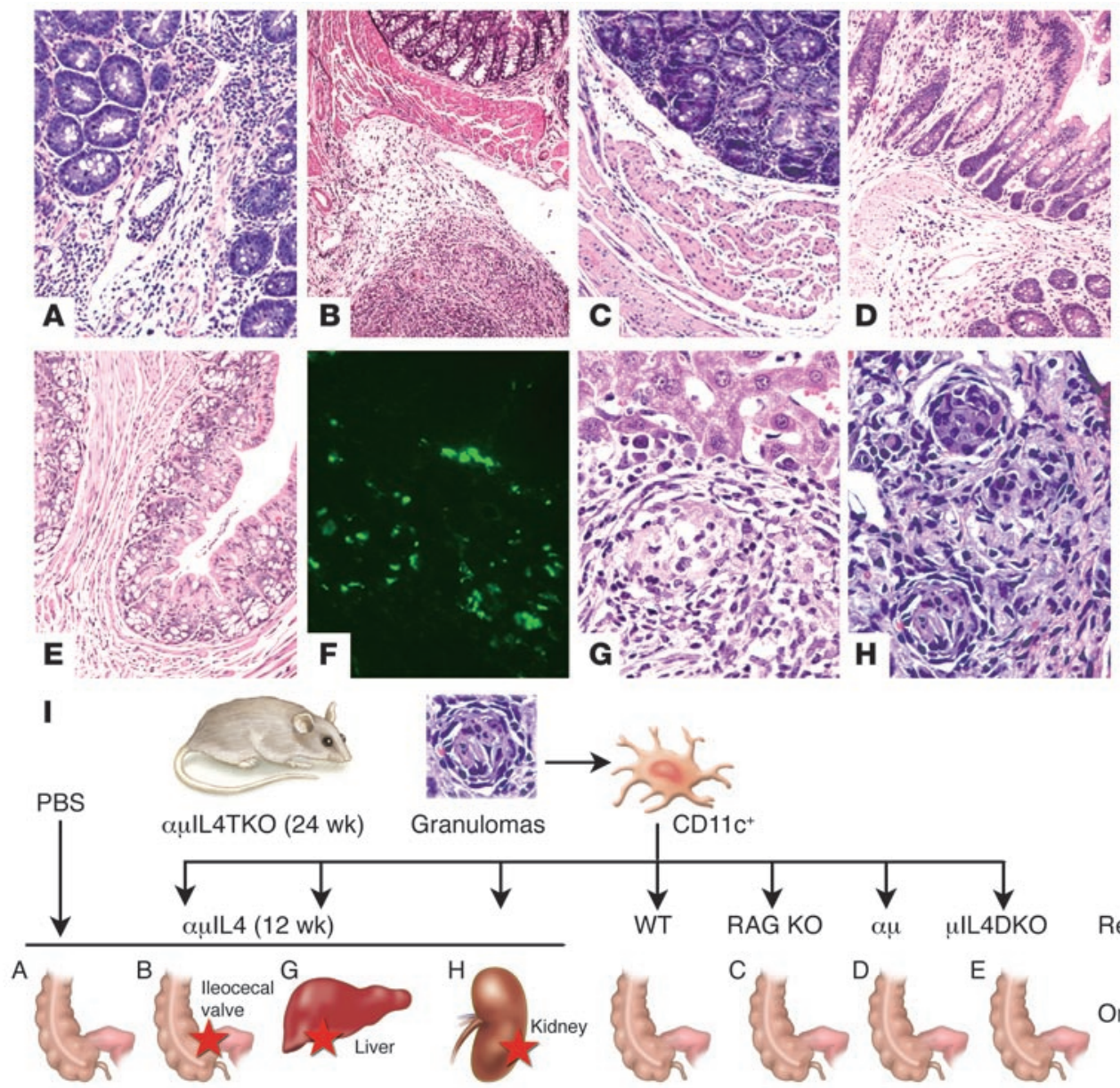

aulL4TKO (24 wk)
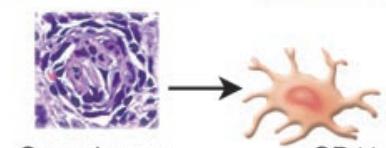

Granulomas

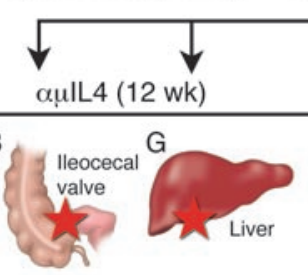

9/16

$4 / 9$
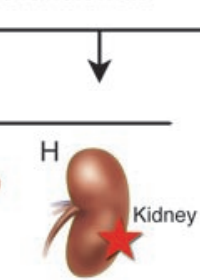

$3 / 8$

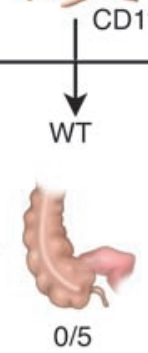

0/5

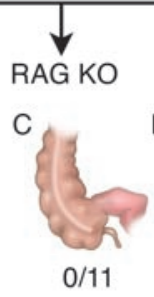

0/11
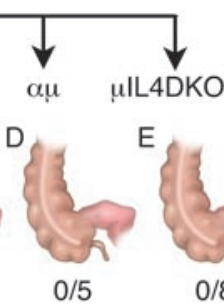

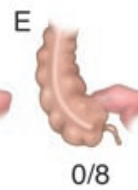

Recipient

Organs

Frequency

Figure 6

Granuloma-derived IMD-like cells possess an ability to directly induce granuloma formation. (A-H) Purified IMDlike cells $\left(3 \times 10^{5}\right)$ from granulomatous lesions of $\alpha$ ulL4TKO mice $(24$ weeks of age) $(\mathbf{B}-\mathbf{E}, \mathbf{G}$, and $\mathbf{H})$ or PBS $(\mathbf{A})$ were injected into the intestinal wall at the ileocecal junction $(\mathbf{A}-\mathbf{E})$, subcapsular areas of the liver $(\mathbf{G})$, and the kidneys (H) in young aulL4TKO mice (9 weeks of age) (A, B, G, and H), RAG-1 KO mice (C), old auDKO mice (24 weeks of age) (D), $\mu$ IL4DKO mice (E). Recipient mice were sacrificed 3 weeks after injection and the organs were subjected to histological examination. (F) Purified CD11 $\mathrm{C}^{+}$cells from granulomatous lesions of $\alpha \mu$ IL4TKO mice (24 weeks of age) were labeled with CSFE and directly injected into the ileocecal junction. Recipient mice were sacrificed 4 days after injection and tissues were subjected to fluorescence microscopic analysis. Accumulation of green fluorescence ${ }^{+}$cells is observed in the injection site. Data are representative of 2 individual experiments. (I) Summary of results of these local cell transfer experiments. Frequencies of granuloma induction are indicated on the bottom line. Red stars indicate tissues in which granuloma formation was induced.

fine dendrites (Figure 3D). After the capture of pathogens, inflammatory monocytes rapidly differentiate into DCs or macrophages; monocytes that remain in the inflammatory site generally differentiate into macrophages $(42,43)$, and intradermal injection of Salmonella blocks the differentiation of monocytes into functional DCs and favors their differentiation into macrophages (44). Although in granulomatous colitis, classical macrophage populations without DC markers exist (data not shown), the majority of CD11 $\mathrm{c}^{+}$cells express the macrophage marker F4/80 (Figure 3 and Supplemental Figure 1). Therefore, it is possible that granuloma-favoring conditions (with impaired IL-4 and IgG production) may disturb the appropriate differentiation pathway of inflammatory monocytes into DCs/macrophages. Indeed, Igs have been shown to induce maturation of DCs $(45,46)$. Furthermore, IL-4 has been widely used
Our local cell-transfer study indicates that IMD-like cells differentiated under intestinal granuloma-inducing microenvironments can induce granuloma development not only in the intestine but also in nonintestinal sites such as liver and kidneys when transferred under Th1-polarized conditions. Therefore, IMD-like cells may also be involved in the development of other Th1-mediated granulomas, such as granulomas associated with bacterial (M. tuberculosis) infection. Indeed, infection by M. tuberculosis induces the development of a unique cell subset sharing both properties of DCs and macrophages in the lung $(6,41)$. The IMD-like cells spontaneously produce large amounts of IL-12p40 that is involved in the development of granulomas in the intestine (Figure 4D) and the skin (7). Since the IMD-like cells mostly express IL-12p40 and p19 but not P35, IL-23 rather than IL-12 may be the crucial cytokine 


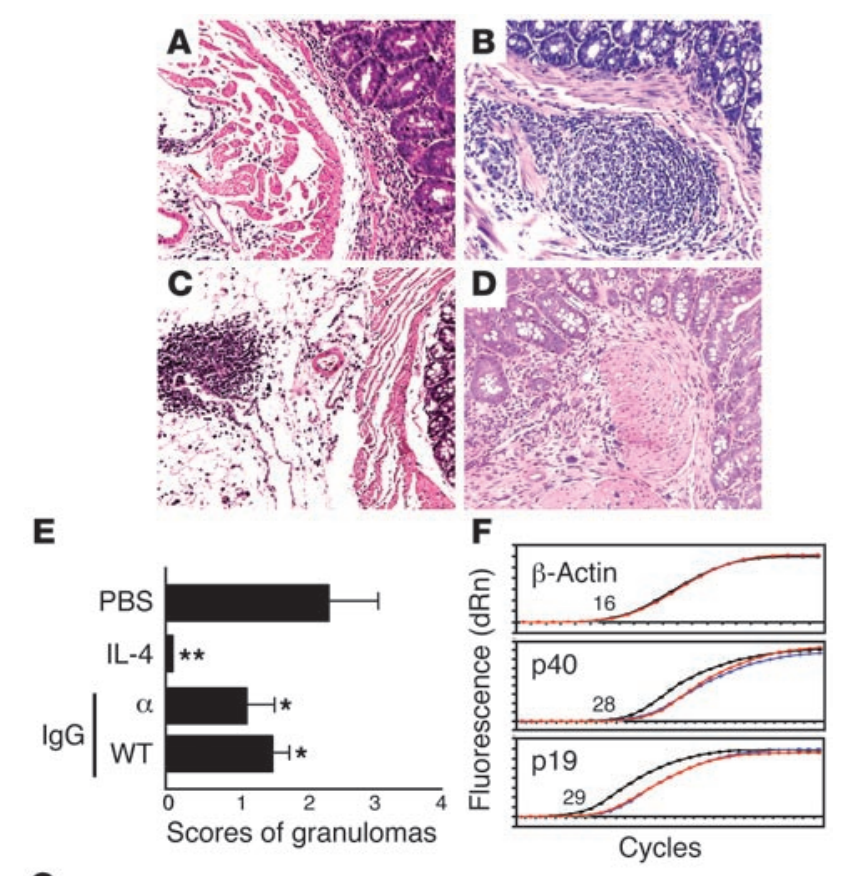

G

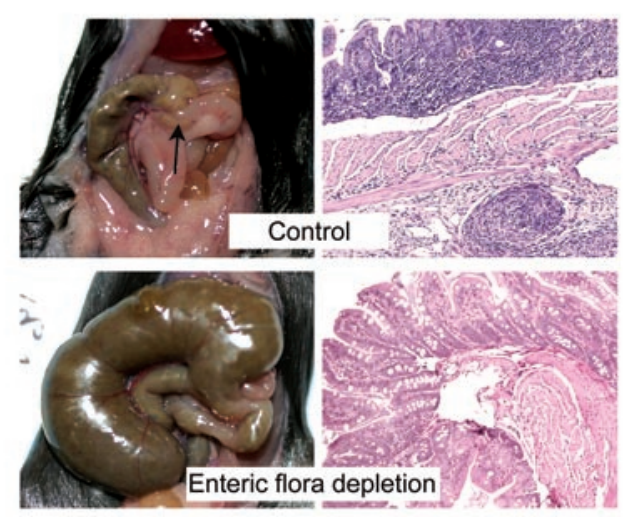

necessary for the development of granulomas (35). Most recently, involvement of the IL-23R-signaling cascade in the pathogenesis of Crohn disease was identified by a genome-wide association study (49). Indeed, a pathogenic role of IL-23 has recently been shown in innate and acquired immune-mediated experimental colitis models (50-53). In contrast, the roles of IL-23 may differ depending on the type of intestinal inflammation, as suggested by a regulatory role of IL-23 in acute colitis models that are induced by dextran sulfate sodium (DSS) or trinitrobenzene sulfonic acid (TNBS) (54).

Importantly, our study also indicates that several factors, including cytokine balance, $\mathrm{B}$ cell function, and enteric bacteria, regulate the ability of IMD-like cells to form granulomas. Host/microbial interactions are considered crucial for the development of chronic intestinal inflammation (24). The production of IL-12p 40 by DCs is enhanced in B cell-deficient mice $(46,55)$ and suppressed by IL-4 $(56,57)$. Engagement of inhibitory Fc receptor FcgRIIB by IgG or as immune complexes is required for the B cell-mediated suppression of S. mansoni-induced granulomas through the activation of an immunoreceptor tyrosine-based inhibition motif(ITIM) (3). In addition, as Fc $\gamma$ RIIB accounts for over $75 \%$ of total FcR expression on DCs (58), IgG generally contributes to the suppression of immune activation by DCs $(45,46,58)$. Our studies indicate that

\section{Figure 7}

Both IL-4 and IgG are required for the regulation of IMD-like cell-mediated granuloma formation. (A-E) $\mathrm{CD} 11 \mathrm{C}^{+}$cells from granulomatous of old $\alpha \mu$ IL4TKO mice were injected into the intestinal wall at the ileocecal junction in young aulL4TKO mice. IL-4 $(\mathbf{A}, n=5)$ or PBS (B, $n=5)$, or IgG from TCR $\alpha$ KO mice $(\mathbf{C}, n=5)$ or WT mice $(\mathbf{D}, n=5)$, were administered into recipient mice. Recipient mice were sacrificed at 3 weeks after local cell transfer. Scores of granulomas are summarized in $\mathbf{E}$. Statistical significance is indicated by asterisks. ${ }^{*} P<0.05$; ${ }^{* *} P<0.0001$. (F) RNA isolated from ileocecal junction of recipient mice with administration of PBS (black line, $n=5$ ), IL-4 (red line, $n=5$ ), or IgG (blue line, $n=5$ ) was subjected to QPCR analysis for the detection of $\beta$-actin, IL-12p40, and p19. Lines represent the averages of 5 mice in each group. (G) Purified CD11 $\mathrm{c}^{+}$cells from granulomas of old $\alpha \mu I L 4 T K O$ mice were injected into the intestinal wall at the ileocecal junction in young $\alpha \mu$ IL4TKO mice without (top panels) or with (bottom panels) depletion of enteric bacteria by treatment with a combination of antibiotics. No granulomas were detectable in the decontaminated recipient mice $(n=8)$. Gross findings (left panels) show no recognizable nodular formation in the ileocecal junction with enlargement of cecum in the mouse with depleted enteric flora (bottom left) versus presence of granuloma formation in the ileocecal junction (arrow) without enlargement in the control mouse with enteric flora (top left).

IL-4 and the Fc portion of IgG can regulate IL-23 production of IMD-like cells, which express both Fc $\gamma$ RII and IL-4R $\alpha$. Indeed, the administration of either IL-4 or IgG led to suppression of granuloma formation induced by local transfer of granuloma-derived IMDlike cells (Figure 7). In addition, in vitro experiments (Figure 5D) showed that both uncoupled IgG and immunocomplexes suppress IL-12p40 production by IMD-like cells.

In summary, we have identified an intestinal granuloma-associated unique $\mathrm{CD} 11 \mathrm{c}^{+}$subset that not only shares phenotypic and functional features with IMDs but also coexpresses a marker associated with macrophages. Importantly, the ability of these unique IMD-like cells to induce granuloma formation is modulated by IL-4, IgG, and enteric flora.

\section{Methods}

Mice. TCR $\alpha$ KO, Igh-6 KO ( $\mu \mathrm{KO})$, IL-4 KO, IFN- $\gamma$ KO, and GFP transgenic mice were purchased from The Jackson Laboratory and were maintained under specific pathogen-free conditions at the Massachusetts General Hospital. These mice were all of C57BL/6 strain (H-2b) background that had been backcrossed with C57BL/ 6 over 8 times. Double-, triple-, and quadruple-KO mice were generated by crossing these mouse strains, as previously described (29). The animal care and procedures of the experiments were approved by the Subcommittee on Research Animal Care, Massachusetts General Hospital.

Isolation of cells. To isolate DCs from the ileocecal junction and colonic LP, the methods for removal of epithelial cells (59), digestion of colonic tissues (60), and isolation of Peyer patch DCs (10) were combined and modified. After anesthetizing mice, $15 \mathrm{ml}$ of $30 \mathrm{mM}$ EDTA/HBSS were perfused through the left ventricle. The colon was removed, inverted, and shaken in $1 \mathrm{mM}$ EDTA/HBSS at 2,516 g for 90 seconds by Mini-Beadbeater (BioSpec Products Inc.). The remaining tissues without epithelial layers were cut into small pieces and incubated with RPMI medium containing $2 \mathrm{mg} / \mathrm{ml}$ collagenase type $2,1 \mathrm{mg} / \mathrm{ml}$ dispase (Invitrogen), $15 \mu \mathrm{g} / \mathrm{ml}$ DNAse (Roche Applied Science), and 4\% FBS with $2 \mathrm{~g}$ shaking and occasional vortexing at $37^{\circ} \mathrm{C}$ for 45 minutes followed by incubation with $5 \mathrm{mM}$ EDTA/PBS at $37^{\circ} \mathrm{C}$ for 5 minutes. The cells were passed through $60-\mu \mathrm{m}$-pore nylon filters and then used as total colonic LP cells. Cells were stained with FITC-conjugated anti-CD11c mAbs, followed by incubation with magnetic beads-conjugated anti-FITC (Miltenyi Biotec). The stained cells were positively sorted, using MACS (Miltenyi Biotec), and purity 

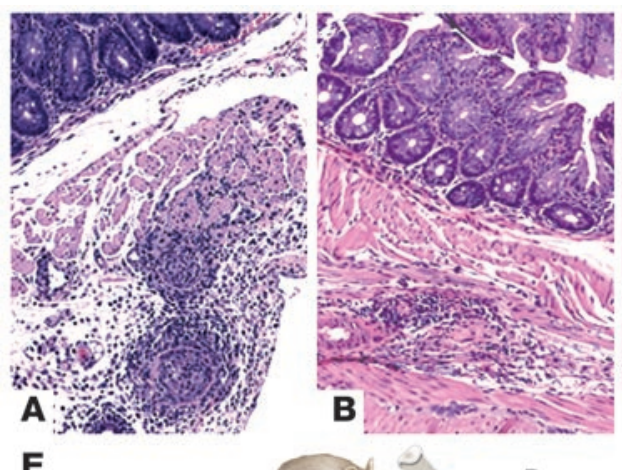

E
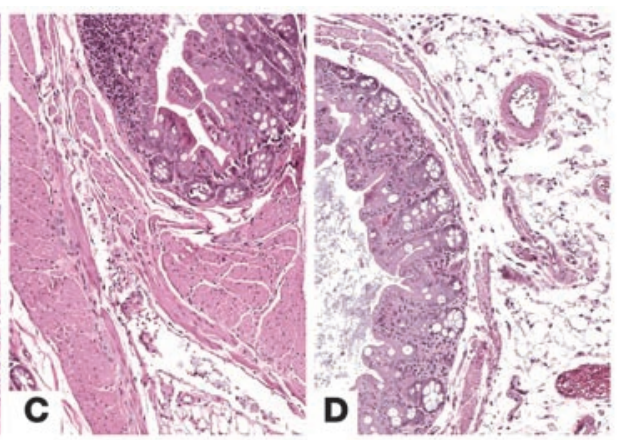

$\mathbf{F}$
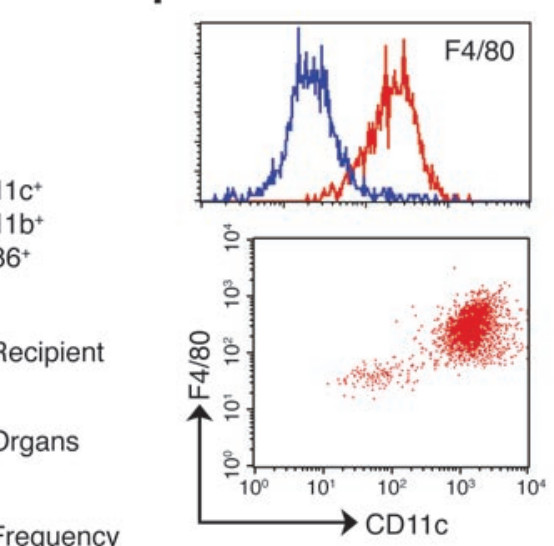

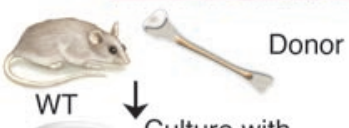

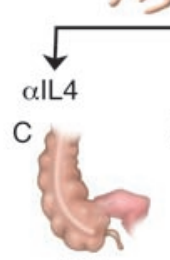

$/ 6$
$0 / 6$
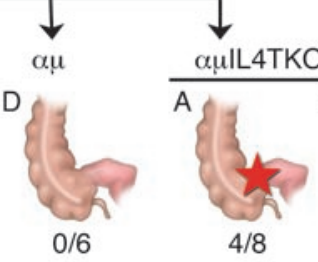

$4 / 8$

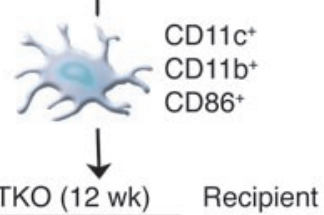

B

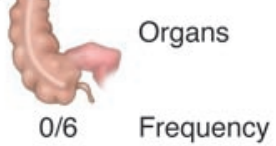

Figure 8

Potential ability of immature DCs to differentiate IMD-like cells capable of inducing granuloma formation. (A-D) BM-derived DCs from WT mice were expanded in in vitro culture with GM-CSF in the presence or absence of LPS. After culture, immature (CD11C+CD11b+CD86-, purity of more than $98 \%)(\mathbf{A}$, C, and $\mathbf{D})$ and mature $\left(C D 11 C^{+} C D 11 b^{+} C D 86\right.$ high, purity of more than $\left.98 \%\right)(B)$ myeloid DCs were purified by FACS sorting. We directly injected $3 \times 10^{5}$ cells into the ileocecal junction of young $\alpha$ ulL4TKO (A and B), $\alpha$ IL4DKO (C), and $\alpha \mu D K O$ (D) mice (9 weeks of age). Recipient mice were sacrificed 3 weeks after injection. (E) Results of these local cell transfer experiments are summarized. Frequencies of granuloma induction are indicated on the bottom line. Red star indicates the tissues in which granuloma formation was induced. (F) BM-derived DCs from GFP transgenic mice were expanded in culture with GM-CSF in vitro. After culture, CD11 $\mathrm{C}^{+}$cells were purified through the MACS system. We injected $3 \times 10^{5}$ cells directly into the ileocecal junction of aulL4TKO mice, and recipient mice were sacrificed 3 weeks after injection. Cells were isolated from the ileocecal junction and subjected to flow cytometric analysis. Top panel shows $\mathrm{F} 4 / 80$ expression on gated $\mathrm{GFP}+\mathrm{CD} 11 \mathrm{c}^{+}$cells before cell injection (blue line) and from the recipient ileocecal junction (red line). F4/80 versus CD11c expression on gated GFP+ cells among the cells isolated from the recipient ileocecal junction is shown (bottom panel). Data are representative of 2 individual experiments.

was confirmed by flow cytometric analysis. In some experiments, after staining with FITC-conjugated anti-CD11c and PE-conjugated anti-F4/80 mAbs, cells were purified using flow cytometric sorting.

Local transfer of DCs. Cells isolated from grossly recognized granulomas were stained with FITC-conjugated anti-CD11c mAbs, then incubated with anti-FITC Microbeads. The stained cells were positively sorted, using MACS, and purity was over $95 \%$. In some experiments, $\mathrm{CD} 11 \mathrm{c}^{+}$cells were purified using biotin-conjugated anti-CD11c/magnetic beads-conjugated streptavidin and then labeled with CFSE (Molecular Probes) according to the manufacturer's instructions. For preparation of BM-derived DCs, BM cells from WT or GFP transgenic mice were subjected to red blood cell lysis and then to negative sorting for the depletion of $\mathrm{B} 220^{+}, \mathrm{Gr}^{+}, \mathrm{NK}-1.1^{+}$, and $\mathrm{CD}^{+}$cells. Remaining cells were cultured with 1,000 U/ml GM-CSF (PeproTech) for 7 days as previously described (61). Cells were then stimulated with or without $1 \mu \mathrm{g} / \mathrm{ml}$ LPS (InvivoGen) for 2 days. For separation of DC subsets from
WT mice, $\mathrm{CD} 11 \mathrm{c}^{+} \mathrm{CD} 11 \mathrm{~b}^{+} \mathrm{CD} 86^{-}$and $\mathrm{CD} 11 \mathrm{c}^{+} \mathrm{CD} 11 \mathrm{~b}^{+} \mathrm{CD} 86^{+}$fractions were purified by flow cytometric sorting after staining cultured cells with FITC-conjugated CD86, PE-conjugated CD11b, and PerCP-conjugated CD11c mAbs. Purities were over $99 \%$. For local transfer of DCs, an abdominal incision was made in anesthetized mice, and $10 \mu \mathrm{l}$ PBS was injected into the intestinal wall at the ileocecal junction and/or subcapsular areas of the liver and kidney, using microinjection needles to make a space for the following cell injection. DCs $\left(3 \times 10^{5}\right)$ in $50 \mu \mathrm{l}$ PBS were then injected using a $28 \mathrm{G}$ needle into the created space.

In some experiments, IL-4 or PBS was continuously delivered in the peritoneal cavity through catheter from an osmotic pump (ALZA) that was implanted in the dorsa of recipient mice as previously described (29).

Depletion of enteric flora was performed as previously described (39). In brief, mice were treated with a combination of ampicillin $(1 \mathrm{~g} / \mathrm{l})$, vancomycin $(500 \mathrm{mg} / \mathrm{l})$, neomycin sulfate $(1 \mathrm{~g} / \mathrm{l})$, and metronidazole $(1 \mathrm{~g} / \mathrm{l})$ in drinking water for 5 weeks prior to transfer of IMD-like cells, and this antibiotic treatment was continued until sacrifice.

Neutralization of IL-12p40 activity. RAG-1 KO mice were injected with hybridomas (C17.8) that produce neutralizing rat antimouse IL-12p40 mAbs to elicit mAb-containing ascites (32). The $\mathrm{mAbs}$ were purified from the ascites fluid. Anti-IL-12p40 $\mathrm{mAbs}$ or control rat IgG $(0.5 \mathrm{mg} /$ injection $)$ was intraperitoneally administered weekly to $\alpha \mu$ IL4TKO mice (16 weeks of age) that had developed colitis, as indicated by the presence of diarrhea, and the mice were sacrificed at 24 weeks of age.

Immunohistochemical and flow cytometric analyses. Fresh tissue samples were frozen in OCT compound and stored at $-80^{\circ} \mathrm{C}$. Frozen tissue sections $(4 \mu \mathrm{m})$ were air dried for 2 hours, fixed in acetone for 10 minutes, air dried again for 20 minutes, and stained by the avidin-biotin complex method (59). Cells $\left(2.5 \times 10^{5}\right)$ were incubated in FACSbuffer $(0.2 \% \mathrm{BSA}, 0.1 \%$ sodiumazide/PBS $)$ containing $10 \%$ normal rat, hamster, and mouse serum (Jackson ImmunoResearch Laboratories Inc.) and $1 \mu \mathrm{g}$ anti-CD16/CD32 (2.4G2) mAbs stained with combinations of FITC, PE, PerCP, or APC conjugated mAbs specific to CD11c (HL3), CD11b (M1/70), CD8 $\alpha$ (clone 53-6.7), I-A b (clone 25-9-17), CD86 (GL1), CD40 (clone 3/23), B220 (clone RA3-6B2), Gr-1 (clone RB6-8C5), and DX-5 (BD Biosciences - Pharmingen), PE-F4/80 (clone BM8; CALTAG Laboratories), or FITC-conjugated MOMA-1 (MOMA-1; Serotec) at $4^{\circ} \mathrm{C}$ for 30 minutes and analyzed on a FACScan Flow Cytometer (BD).

Functional assays. To assess endocytosis activity of DCs, FITC-dextran was used according to the method described previously $(8,61)$. In brief, cells were incubated in $0.1 \mathrm{mg} / \mathrm{ml}$ of FITC-dextran (Invitrogen) at $37^{\circ} \mathrm{C}$ for 
30 minutes. Control incubations were performed at $4^{\circ} \mathrm{C}$. After washing, cells were stained with PerCP-conjugated anti-CD11c and PE-CD11b mAbs. For mixed lymphocyte reaction, enriched $\mathrm{T}$ cells $\left(1 \times 10^{5}\right)$ from $\mathrm{BALB} / \mathrm{c}$ mice, using a $\mathrm{T}$ cell enrichment column ( $\mathrm{R} \& \mathrm{D}$ Systems) were cultured without or with $2 \times 10^{4}$ of WT (C57BL/6) BM-derived mature DCs or $\alpha \mu$ IL4TKO (C57BL/6) granuloma-derived CD11 $c^{+}$cells for 80 hours and pulsed with $1 \mu \mathrm{Ci}{ }^{3} \mathrm{H}$ for 16 hours, as previously described (61).

Detection of cytokines. Cells in $150 \mu \mathrm{l}$ F12/DMEM medium containing $1 \%$ FBS, $1 \times$ SITE3 (Sigma-Aldrich), $10 \mathrm{mM}$ sodium pyruvate, and $50 \mu \mathrm{M}$ 2 -mercaptoethanol were cultured for 48 hours. In some experiments, the cells were cultured with additives. The culture supernatants were subjected to OptEIA ELISA (BD Biosciences - Pharmingen) for the detection of IL-12p40, p70, and IFN- $\gamma$ and to Ready-SET-Go! ELISA (eBioscience) for detection of IL-23 according to the manufacturers' instructions. Total RNA was extracted from the mucosal layer of the colon and/or ileocecal junction areas. RPAs were performed using $10 \mu \mathrm{g}$ of total RNA with the RiboQuant Multi-Probe RPA System (BD Biosciences - Pharmingen), as previously described (59). Real-time RT-PCR was performed using cDNA from $2.5 \times 10^{5}$ purified cells as previously described (60). The primers used were as follows: forward, 5 -ACTCTGAGCCACTCACATCT and reverse, 5'-GCTGGTGCTGTAGTTCTCAT for IL-12p40; forward, 5' -GAAGACCTGTTTACCACTGG and reverse, 5'-TCACTCTGTAAGGGTCTGCT for IL-12p35; forward, 5'-AGATGCTGGATTGCAGAGCA and reverse, 5'AGGTGTGAAGTTGCTCCATG for IL-23 (p19); forward, 5'-TCAGAC-
TACCTCAACCGTTC and reverse, 5' -TCTCGACCCTGAAAGTGAAG for IL-17A; and forward, 5'-ATTCTGAGGGAGGTAGCAGC and reverse, 5'AGTGATGTTGTAATCCCATG for IL-17F.

Statistics. Statistical analysis was performed using the Mann-Whitney $U$ test. $P$ values of less than 0.05 were considered statistically significant.

\section{Acknowledgments}

We would like to thank Robert T. McCluskey, Cathy Nagler, and Hiromichi Ishikawa for their helpful comments and advice and H.J. Winn for kindly providing anti-IL-12p40 mAbs (clone C17-8 provided by C. Trinchieri). This study was supported by NIH grant DK47677 (to A.K. Bhan); NIH grant DK064351 and the Eli and Edythe L. Broad Medical Research Program (to A. Mizoguchi); NIH grants DK44319, DK51362, and DK53056 (to R.S. Blumberg); and DK64289 (to E. Mizoguchi); and the Center for the Study of Inflammatory Bowel Disease (Massachusetts General Hospital).

Received for publication August 23, 2006, and accepted in revised form December 19, 2006.

Address correspondence to: Atsushi Mizoguchi, Simches 8234, Massachusetts General Hospital, 185 Cambridge Street, Boston, Massachusetts 02114, USA. Phone: (617) 726-8492; Fax: (617) 643-3566; E-mail: amizoguchi@partners.org.
1. Kaufmann, S.H. 1993. Immunity to intracellular bacteria. Annu. Rev. Immunol. 11:129-163.

2. Sandor, M., Weinstock, J.V., and Wynn, T.A. 2003. Granulomas in schistosome and mycobacterial infections: a model of local immune responses. Trends Immunol. 24:44-52.

3. Jankovic, D., et al. 1998. CD4 ${ }^{+}$T cell-mediated granulomatous pathology in schistosomiasis is downregulated by a B cell-dependent mechanism requiring FC receptor signaling. J. Exp. Med. 187:619-629.

4. Yoneyama, H., et al. 2001. Regulation by chemokines of circulating dendritic cell precursors, and the formation of portal tract-associated lymphoid tissue, in a granulomatous liver disease. J. Exp. Med. 193:35-49.

5. Chiu, B.C., et al. 2004. The innate pulmonary granuloma. Am. J. Pathol. 164:1021-1030.

6. Ordway, D., Henau-Tamayo, M., Orme, I.M., and Gonzalez-Juarrero, M. 2005. Foamy macrophages within lung granulomas of mice infected with Mycobacterium tuberculosis express molecules characteristic of dendritic cells and antiapoptotic markers of the TNF receptor-associated factor family. J. Immunol. 175:3873-3881.

7. Ashkar, S., et al. 2000. Eta-1 (osteopontin): an early component of type-1 (cell-mediated) immunity. Science. 287:860-864.

8. Mellman, I., and Steinman, R.M. 2001. Dendritic cells: specialized and regulated antigen processing machines. Cell. 106:255-258.

9. Ardavin, C. 2003. Origin, precursors and differentiation of mouse dendritic cells. Nat. Rev. Immunol. 3:582-590.

10. Iwasaki, A., and Kelsall, B.L. 1999. Freshly isolated Peyer's patch, but not spleen, dendritic cells produce interleukin 10 and induce the differentiation of T helper type 2 cells. J. Exp. Med. 190:229-239.

11. Bell, S.J., et al. 2001. Migration and maturation of human colonic dendritic cells. J. Immunol. 166:4958-4967.

12. Chirdo, F.G., Millington, O.R., Beacock-Sharp, H., and Mowat, A.M. 2005. Immunomodulatory dendritic cells in intestinal lamina propria. Eur. J. Immunol. 35:1831-1840.

13. Turnbull, E.L., Yrlid, U., Jenkins, C.D., and
MacPherson, G.G. 2005. Intestinal dendritic cell subsets: differential effects of systemic TLR4 stimulation on migratory fate and activation in vivo. J. Immunol. 174:1374-1384.

14. Huang, F.P., et al. 2000. A discrete subpopulation of dendritic cells transports apoptotic intestinal epithelial cells to $T$ cell areas of mesenteric lymph nodes. J. Exp. Med. 191:435-444.

15. Rescigno, M., et al. 2001. Dendritic cells express tight junction proteins and penetrate gut epithelial monolayers to sample bacteria. Nat. Immunol. 2:361-367.

16. Niess, J.H., et al. 2005. CX3CR1-mediated dendritic cell access to the intestinal lumen and bacterial clearance. Science. 307:254-258.

17. Bilsborough, J., and Viney, J.L. 2004. Gastrointestinal dendritic cells play a role in immunity, tolerance, and disease. Gastroenterology. 127:300-309.

18. Macpherson, A.J., and Uhr, T. 2004. Induction of protective IgA by intestinal dendritic cells carrying commensal bacteria. Science. 303:1662-1665.

19. Rimoldi, M., et al. 2005. Intestinal immune homeostasis is regulated by the crosstalk between epithelial cells and dendritic cells. Nat. Immunol. 6:507-514.

20. Malmstrom, V., et al. 2001. CD134L expression on dendritic cells in the mesenteric lymph nodes drives colitis in T cell-restored SCID mice. J. Immunol. 166:6972-6981.

21. Krajina, T., Leithauser, F., Moller, P., Trobonjaca, Z., and Reimann, J. 2003. Colonic lamina propria dendritic cells in mice with $\mathrm{CD}^{+} \mathrm{T}$ cell-induced colitis. Eur. J. Immunol. 33:1073-1083.

22. Annacker, O., et al. 2005. Essential role for CD103 in the $\mathrm{T}$ cell-mediated regulation of experimental colitis. J. Exp. Med. 202:1051-1061.

23. Podolsky, D.K. 2002. Inflammatory bowel disease. N. Engl. J. Med. 347:417-429.

24. Sartor, R.B. 2004. Therapeutic manipulation of the enteric microflora in inflammatory bowel diseases: antibiotics, probiotics, and prebiotics. Gastroenterology. 126:1620-1633.

25. Powrie, F. 1995. T cells in inflammatory bowel disease: protective and pathogenic roles. Immunity. 3:171-174.

26. Blumberg, R.S., Saubermann, L.J., and Strober, W. 1999. Animal models of mucosal inflammation and their relation to human inflammatory bowel disease. Curr. Opin. Immunol. 11:648-656.

27. Bhan, A.K., Mizoguchi, E., Smith, R.N., and Mizoguchi, A. 1999. Colitis in transgenic and knockout animals as models of human inflammatory bowel disease. Immunol. Rev. 169:195-207.

28. Iijima, H., et al. 1999. Alteration of interleukin 4 production results in the inhibition of $\mathrm{T}$ helper type 2 cell-dominated inflammatory bowel disease in $\mathrm{T}$ cell receptor $\alpha$ chain-deficient mice. J. Exp. Med. 190:607-616.

29. Mizoguchi, A., Mizoguchi, E., and Bhan, A.K. 1999. The critical role of IL-4 but not IFN- $\gamma$ in the pathogenesis of chronic colitis in T cell receptor $\alpha$ mutant mice. Gastroenterology. 116:320-326.

30. Smelt, S.C., Cotterell, S.E., Sgwerda, C.R., and Kaye, P.M. 2000. B cell-deficient mice are highly resistant to Leishmania donovani infection, but develop neutrophil-mediated tissue pathology. J. Immunol. 164:3681-3688.

31. Neurath, M.F., Finotto, S., and Glimcher, L.H. 2002. The role of Th1/Th2 polarization in mucosal immunity. Nat. Med. 8:567-573.

32. Trinchieri, G. 1994. Interleukin-12: a cytokine produced by antigen-presenting cells with immunoregulatory functions in the generation of $\mathrm{T}$ helper cell type 1 and cytotoxic lymphocytes. Blood. 84:4008-4027.

33. Oppmann, B., et al. 2000. Novel p19 protein engages IL-12p40 to form a cytokine, IL-23, with biological activities similar as well as distinct from IL-12. Immunity. 13:715-725.

34. Becker, C., et al. 2003. Constitutive $\mathrm{p} 40$ promoter activation and IL-23 production in the terminal ileum mediated by dendritic cells. J. Clin. Invest. 112:693-706. doi:10.1172/JCI200317464.

35. Langrish, C.L., et al. 2004. IL-12 and IL-23: master regulators of innate and adaptive immunity. Immunol. Rev. 202:96-105.

36. Takeda, K., Kaisho, T., and Akira, S. 2003. Toll-like receptors. Annu. Rev. Immunol. 21:335-376.

37. Murphy, C.A., et al. 2003. Divergent pro- and antiinflammatory roles for IL-23 and IL-12 in joint autoimmune inflammation. J. Exp. Med. 198:1951-1957.

38. Weaver, C.T., Harrington, L.E., Mangan, P.R., Gavrieli, M., and Murphy, K.M. 2006. Th17: an effector CD4 
$\mathrm{T}$ cell lineage with regulatory $\mathrm{T}$ cell ties. Immunity. 24:677-688.

39. Rakoff-Nahoum, S., Paglino, J., Eslami-Varzaneh, F., Edberg, S., and Medzhitov, R. 2004. Recognition of commensal microflora by toll-like receptors is required for intestinal homeostasis. Cell. 118:229-241.

40. Falk, P.G., Hooper, L.V., Midtvedt, T., and Gordon, J. 1998. Creating and maintaining the gastrointestinal ecosystem: what we know and need to know from gnotobiology. Microbiol. Mol. Biol. Rev. 62:1157-1170.

41. Peters, W., et al. 2004. CCR2-dependent trafficking of F4/80 dim macrophages and CD $11 \mathrm{c}^{\mathrm{dim} / \text { intermediate }}$ dendritic cells is crucial for $\mathrm{T}$ cell recruitment to lungs infected with mycobacterium tuberculosis. J. Immunol. 172:7647-7653.

42. Randolph, G.J., Inaba, K., Robbiani, D.F., Steinman, R.M., and Muller, W.A. 1999. Differentiation of phagocytic monocytes into lymph node dendritic cells in vivo. Immunity. 11:753-761.

43. Krutzik, S.R., et al. 2005. TLR activation triggers the rapid differentiation of monocytes into macrophages and dendritic cells. Nat. Med. 11:653-660.

44. Rotta, G., et al. 2003. Lipopolysaccharide or whole bacteria block the conversion of inflammatory monocytes into dendritic cells in vivo. J. Exp. Med. 198:1253-1263.

45. Regnault, A.D., et al. 1999. Fcy receptor-mediated induction of dendritic cell maturation and major histocompatibility complex class I-restricted antigen presentation after immune complex internalization. J. Exp. Med. 189:371-380.

46. Bayry, J., et al. 2005. Modulation of dendritic cell maturation and function by B lymphocytes. J. Immunol. 175:15-20.

47. Lutz, M.B., et al. 2000. Immature dendritic cells generated with low dose of GM-CSF in the absence of IL-4 are maturation-resistant and prolong allograft survival in vivo. Eur. J. Immunol. 30:1813-1822.

48. Martin, E., O'Sullivan, B., Low, P., and Thomas, R. 2003. Antigen-specific suppression of a primed immune response by dendritic cells mediated by regulatory $\mathrm{T}$ cells secreting interleukin-10. Immunity. 18:155-167.

49. Duerr, R.H., et al. 2006. A genome-wide association identifies $I L 23 R$ as an inflammatory bowel disease gene. Science. 314:1461-1463.

50. Uhlig, H.H., et al. 2006. Differential activity of IL-12 and IL-23 in mucosal and systemic innate immune pathology. Immunity. 25:309-318.

51. Yen, D., et al. 2006. IL-23 is essential for T cellmediated colitis and promotes inflammation via IL-17 and IL-6. J. Clin. Invest. 116:1310-1316. doi:10.1172/JCI21404.

52. Hue, S., et al. 2006. Interleukin-23 drives innate and $\mathrm{T}$ cell-mediated intestinal inflammation. J. Exp. Med. 203:2473-2483.

53. Kullberg, M.C., et al. 2006. IL-23 plays a key role in Helicobacter hepaticus-induced T cell-dependent colitis. J. Exp. Med. 203:2485-2494.
54. Becker, C., et al. 2006. Cutting edge: IL-23 crossregulates IL-12 production in T cell-dependent experimental colitis. J. Immunol. 177:2760-2764.

55. Moulin, V., et al. 2000. B lymphocytes regulate dendritic cell (DC) function in vivo: increased interleukin 12 production by DCs from B cell-deficient mice results in T helper cell type 1 deviation. J. Exp. Med. 192:475-482.

56. Hochrein, H., et al. 2000. Interleukin (IL)-4 is a major regulatory cytokine governing bioactive IL-12 production by mouse and human dendritic cells. J. Exp. Med. 192:823-830.

57. Pirhonen, J., Matikainen, S., and Julkunen, I. 2002. Regulation of virus-induced IL-12 and IL-23 expression in human macrophages. J. Immunol. 169:5673-5678.

58. Kalergis, A.M., and Ravetch, J.V. 2002. Inducing tumor immunity through the selective engagement of activating Fcy receptors on dendritic cells. J. Exp. Med. 195:1653-1659.

59. Mizoguchi, E., et al. 2003. Colonic epithelial functional phenotype varies with type and phase of experimental colitis. Gastroenterology. 125:148-161.

60. Hokama, A., et al. 2004. Induced reactivity of intestinal $\mathrm{CD}^{+} \mathrm{T}$ cells with an epithelial cell lectin, galectin-4, contributes to exacerbation of intestinal inflammation. Immunity. 20:681-693.

61. Inaba, K., et al. 1992. Generation of large numbers of dendritic cells from mouse bone marrow cultures supplemented with granulocyte/macrophage colony-stimulating factor. J. Exp. Med. 176:1693-1702. 